\title{
Research Article \\ Effect of nutrition improvement program implementation on stunting in children under two years old
}

Yolanda Handayani ${ }^{1}$, Martya Rahmaniati Makful ${ }^{1}$

\section{Abstract}

\section{Dikirim:}

21 Desember 2018

Diterima:

25 Januari 2019
Purpose: The first thousand days of life is a critical momentum where children from the age of 2 years need the best nutrition for brain development. This study examined the effect of appropriate timing of supplementary feeding and vitamin A consumption on nutritional status of children below age of two. Method: The design of this study is cross sectional. The sample in this study is based on data of the Nutritional Status Monitoring 2017 which is amounted to 27.208 , consisting of pregnant women who took iron folate supplementation (TTD); mother gave early breastfeeding initiation, exclusive breastfeeding, and supplementary food; children who received vitamin A; and children who get height measurement by age. Results: The odds of mothers not providing supplementary feeding to children aged 7-23 months have a short nutritional status 1,137 times greater than mothers who provide supplementary feeding. While the Vitamin A variable has odds ratio 0,659 significantly, the odds of children not getting Vitamin A have short nutritional status 0,659 times greater than children who received Vitamin A. Conclusion: The risk of stunting occurs in a period of 6 to 24 months due to the period for growth in height. Health workers at the primary health care should inform mothers to provide supplementary food and vitamin A at the 6-24 month of age.

Keywords: stunting; supplementary food; vitamin A

\footnotetext{
${ }^{1}$ Biostatistic and Population Studies University of Indonesia Department of Faculty of Public Health, A Building 2 nd Floor of New Campus UI Depok 16424, Indonesia
} 


\section{INTRODUCTION}

The first thousand days of life (from conception until a child is 2 years old) are critical moments that will determine the quality of the future of nation, also known as the golden period. If it is not used properly, there will be permanent damage (window of opportunity) (1). In this period, most children will be given the best nutrition for brain development. Nutrition needed will be used to lay the groundwork for cognitive skills, motor and social development in the future, as well as the success and productivity of school (2).

Nutrition given to children in the first 1000 days of life is generally in the form of nutritional intake during pregnancy. One of the nutritional intake during pregnancy is iron folate supplementation or blood tablet (TTD). The study in Nepal showed that pregnant women taking iron folate supplements can improve general intellectual development, such as some aspects of executive function, and motor function, including fine motor control in children aged 7-9 years in rural Nepal which is very common in iron deficiency (3).

In addition, nutritions that is also good for children during the first 1000 days of life are breast milk and food that is appropriate for the age of the child (4). Data from UNICEF in 2012 showed that the percentage of infants in Indonesia in 2000-2011 included exclusively breastfed infants from ages 0-6 months, namely 32\%, breastfed infants and supplementary foods which were $75 \%$, as well as children who were breastfed until the age of 2 years is $50 \%$, the conclusion is Indonesia can be categorized as fair in feeding for children aged 0-23 months. This show widespread of nutritional deficiencies during the vulnerable period from ages 6 to 9 months, which if added to the infection of the disease, will exacerbate the loss of essential nutrients for growth (5).

If seen from the current nutritional status problem, poor nutritional status is still present in most of the children under 2 years old in Indonesia, as described in the 2017 PSG data following 20,1\% stunting (short); 12,8\% wasting (thin); and $14,8 \%$ underweight (malnutrition). Among stunting children under 2 years old $20,1 \%$, as many as $9,8 \% \%$ children in very short nutritional status and 19,8\% children in short nutritional status (6). Stunting generally occurs before the age of 2 years, and the effect is very irreversible. These include delayed motor development, impaired cognitive function and poor school performance (5).

Based on the first 1000 days program of human life by Indonesian Presidential Regulation No. 42 of 2013 accelerated improvement of nutrition and Regulation of the Minister of Health of the Republic of Indonesia Number 23 of 2014 on efforts to improve nutrition, as well as the recommendations of the experts that the children are given interventions to improve nutrition starting when the mother is pregnant with taking blood tablets
(TTD), then exclusively breastfed from ages 0-6 month and breastfed until the aged 2 years plus age-appropriate complementary food, nutrition safe, as well as getting vitamin A $(4,7)$. Therefore, the researchers wanted to know the relationship of of nutrition improvement intervention programs in the first 1000 days of life to the nutritional status of children under five years of age in Indonesia in 2017.

\section{METHOD}

This study used a cross sectional research design. The dependent variable of this research is stunting which is the results of anthropometric measurements for assessing body children under 2 years old according to the index Height by Age (TB/U) with short category (z-score $<-2 S D)$ and normal (z-score $\geq-2 S D)$. Independent variable this research that blood supplementation, initiation of breastfeeding, exclusive breastfeeding, complementary feeding, and vitamin A. The population of research in the research is a pregnant woman whom the interventions to improve nutrition and children under 2 years old who get intervention to improve nutrition at the time of the survey or five years before the survey as many as 143.634 . The sample is pregnant women who consume iron folate supplementation (TTD), mothers gave initiation of breastfeeding to newborns, mothers gave exclusive breastfeeding to infants aged 0-6 months, mothers provided supplementary feeding to child aged 7-23 months, children under 2 years old who got vitamin A, and children under 2 years old who got measured nutritional status at the time of the survey or five years before the survey with a total sample of 27.208.

This study uses secondary data in the form of nutritional status data and nutrition improvement intervention data in all rural and urban areas of Indonesia which are the results of Nutritional Status Monitoring by the Nutrition Directorate. The sampling technique on Monitoring Nutritional Status that is specifying 30 clusters per district/city with a system of random sampling by Probability Proportional to Size (PPS) which is the sampled in 10 households per cluster by circling the centre point of the cluster. Data analysis used was descriptive analysis, analysis of relationships between variables, and modeling analysis using logistic regression analysis. Nutrition Ministry of Health of the Republic of Indonesia, which was approved by the Health Research Ethics Commission, Health Research and Development Agency on July 19 2017 with letter number LB.02.01/2/KE.244/2017.

\section{RESULTS}

Table 1 shows $20,6 \%$ of children under 2 years old have short nutritional status based on Height by Age (TB/U). 
Also known as much 4.941 (18,2\%) pregnant women did not consume Iron Folate Supplementation (TTD) during pregnancy, as many as 12.448 (45,8\%) mothers did not gave Early Breastfeeding Initiation (IMD), as many as 18.157 (66,7\%) mothers did not Exclusive breastfeeding until the age of 6 months, as many as $17.866(65,7 \%)$ mothers did not provide supplementary feeding to children aged 7-23 months, as well as 7.037 (25,9\%) children under 2 years of old who do not receive Vitamin A.

Table 2 shows that $22,1 \%$ of mothers who did not get Iron Folate Supplementation (TTD) during pregnancy has short nutritional status, with odds ratio 1,055 times greater than mothers who get Iron Folate Supplementation (TTD). A total of $2.629(21,1 \%)$ of mothers who did not give Early Initiation of Breastfeeding (IMD) after the baby is born up to 24 hours of first having short children under 2 years of old nutritional status, with odds ratio 1,047 times greater than mother who provide Early Breastfeeding Initiation (IMD). In addition, a total of $3.709(20,4 \%)$ mothers who

Table 1. Respondent Frequency Distribution of Pregnant Women, Breastfeeding Mothers, and Children under 2 years old

\begin{tabular}{llrr}
\hline \multicolumn{1}{c}{ Variable } & Category & \multicolumn{1}{c}{ n } & \% \\
\hline \multirow{2}{*}{ Height by Age } & Normal & 21.613 & 79,4 \\
& Short & 5.595 & 20,6 \\
Iron Folate & Enough & 8.468 & 32,1 \\
Supplementation & Less & 13.799 & 50,7 \\
(TTD) & No & 4.941 & 18,2 \\
& IMD $\geq 1$ hour & 1.677 & 6,2 \\
Early Breastfeeding & IMD <1 hour & 13.083 & 48,1 \\
Initiation (IMD) & No IMD & 12.448 & 45,8 \\
& Yes & 9.051 & 33,3 \\
Exclusive & Not & 18.157 & 66,7 \\
breastfeeding & Yes & 9.342 & 34,3 \\
Supplementary & Not & 17.866 & 65,7 \\
Feeding & Yes & 20.171 & 74,1 \\
Vitamin A & Not & 7.037 & 25,9 \\
\hline TOTAL & & 27.208 & 100,0 \\
\hline
\end{tabular}

did not exclusively breastfeed for 6 months had a short nutritional status, with odds ratio 0,975 times greater than mothers who exclusively breastfeed for 6 months.

Also known as $3.766(21,1 \%)$ mothers who do not provide supplementary feeding children aged 7-23 months have a short nutritional status, with odds ratio 1,097 times greater than mothers who provide supplementary feeding. And a total of 1.125 $(15,9 \%)$ children who did not get Vitamin A have short nutritional status, with odds ratio 0,668 times greater than children who get Vitamin A.

Table 2 also indicates the contribution of granting Iron Folate Supplementation (TTD) ( $p$-value: 0,0130< 0,25), Early Breastfeeding Initiation (IMD) ( $p$-value: 0,0683 $<0,25$ ), Supplementary Feeding ( $p$-value: 0,0003 < 0,25), and Vitamin A ( $p$-value: $0,00001<0,25$ ) on nutritional status. The results of the modeling analysis of the 4 variables decided to issue variables of Iron Folate Supplementation (TTD) and Early Breastfeeding Initiation (IMD) because it has $p$-value $>0,05$ and there is no other variable that has a change in the odds ratio of more than $10 \%$. In addition, also no others variable which has $p$-value $>0,05$. So, the variables that are the final model are Supplementary Feeding and Vitamin A.

Table 3 shows the supplementary feeding and Vitamin A correlates significantly with the Height by Age nutritional status. Supplementary feeding variable which had odds ratio 1,137 means that the odds of mothers nor providing supplementary feeding to children aged 7-23 months have a short nutritional status 1,137 times greater than mothers who provide supplementary feeding. While the Vitamin A variable has odds ratio 0,659 significantly, the odds of children not getting Vitamin A have short nutritional status 0, 659 times greater than children who received Vitamin A. In this study, not providing supplementary food was a risk factor for stunting while not providing vitamin A became a protective factor for stunting.

Table 2 Frequency Distribution of Nutrition Improvement Intervention Program with Children under 2 years of old Nutritional Status

\begin{tabular}{|c|c|c|c|c|c|c|c|}
\hline \multirow{2}{*}{ Variable } & \multirow{2}{*}{ Category } & \multicolumn{2}{|c|}{ Short } & \multicolumn{2}{|c|}{ Normal } & \multirow{2}{*}{ p-value } & \multirow{2}{*}{$\begin{array}{c}\text { OR } \\
(95 \% \mathrm{CI})\end{array}$} \\
\hline & & $\mathbf{n}$ & $\%$ & n & $\%$ & & \\
\hline \multirow{3}{*}{$\begin{array}{l}\text { Iron Folate Supplementation } \\
\text { (TTD) }\end{array}$} & No & 1.092 & 22,1 & 3.849 & 77,9 & \multirow{3}{*}{$0,0130 *$} & \multirow{3}{*}{$\begin{array}{c}1,055 \\
(1,011-1,101)\end{array}$} \\
\hline & Less & 2.800 & 20,3 & 10.999 & 79,7 & & \\
\hline & Enough & 1.703 & 20,1 & 6.765 & 79,9 & & \\
\hline \multirow{3}{*}{$\begin{array}{l}\text { Early Breastfeeding Initiation } \\
\text { (IMD) }\end{array}$} & IMD $\geq 1$ hour & 341 & 20,3 & 1.336 & 79,7 & \multirow{3}{*}{$0,0683^{*}$} & \multirow{3}{*}{$\begin{array}{c}1,047 \\
(0,997-1,099)\end{array}$} \\
\hline & IMD < 1 hour & 2.625 & 20,1 & 10.458 & 79,9 & & \\
\hline & No IMD & 2.629 & 21,1 & 9.819 & 78,9 & & \\
\hline \multirow{2}{*}{ Exclusive breastfeeding } & Not & 3.709 & 20,4 & 14.448 & 79,6 & \multirow{2}{*}{0.4304} & 0,975 \\
\hline & Yes & 1.886 & 20,9 & 7.165 & 79,2 & & $(0,916-1,038)$ \\
\hline \multirow{2}{*}{ Supplementary Feeding } & Not & 3.766 & 21,1 & 14.100 & 78,9 & \multirow{2}{*}{$0.0003^{*}$} & 1,097 \\
\hline & Yes & 1.829 & 19,6 & 7.513 & 80,4 & & $(1,031-1,168)$ \\
\hline \multirow{2}{*}{ Vitamin A } & Not & 1.125 & 15,9 & 5.912 & 84,1 & \multirow{2}{*}{$0,00001^{*}$} & 0,668 \\
\hline & Yes & 4.470 & 22,2 & 15.701 & 77,8 & & $(0,220-0,718)$ \\
\hline
\end{tabular}

* p-value $<0,25$ 
Table 3. Logistics Regression Nutrition Improvement Intervention Program with Children under 2 years of old Nutritional Status

\begin{tabular}{lcllc}
\hline \multicolumn{1}{c}{$\begin{array}{c}\text { Independent } \\
\text { Variable }\end{array}$} & p-value & $\boldsymbol{\beta}$ & OR & $\mathbf{9 5 \%}$ CI \\
\hline $\begin{array}{l}\text { Supplementary } \\
\text { Feeding }\end{array}$ & 0,00001 & 0,128 & 1,137 & $1,067-1,210$ \\
Vitamin A & 0,00001 & $-0,416$ & 0,659 & $0,614-0,709$ \\
\hline
\end{tabular}

\section{DISCUSSION}

Based on the results of the modeling analysis, the Vitamin A variable has a smaller odds ratio value than Supplementary Feeding variable. This is not in line with the results of studies showed that Vitamin A supplementation is the dominant influence variable (p-value: 0,00001; OR: 2,402; 95\%CI: 1,573-3,668) (8). In addition, the results of other studies also showed that children aged $<24$ months who consume vitamin A supplementation had a high increase of $0,10 \mathrm{~cm}$ greater than in the placebo groups. This confirms that vitamin A supplementation slightly increases overall linear growth, especially for vitamin A deficient children. Children who are older and not breastfed are more visible in linear growth than consumption of vitamin A supplementation compared to children who are more young and breastfed (9).

Vitamin A is needed to support children's immune systems and helps to face a higher risk of death from infectious diseases such as measles and diarrhea. Vitamin A supplementation given regularly to children aged 6 to 59 months has also been shown to be very effective in preventing vitamin A deficiency which can lead to blindness, and can reduce mortality from common diseases $(5,10)$.

While the Supplementary Feeding variable is the dominant variable in this study with odds ratio of 1,137. This is in line with the results of a study that showed that the practice of giving inappropriate supplementary feeding brought a stunting risk of 12,04 times greater than those with appropriate complementary feeding practices (OR $=12,04 ; 95 \% \mathrm{CI}: 5,02-28,89)$. This is because 6 to 24 months is one of the most important periods for linear growth, and also is the peak time of stunting prevalence in developing countries, because of the high dietary needs and the limited quality and quantity of complementary feeding (11). Thus, the process of providing complementary foods is associated with changes in macronutrient and micronutrient intake resulting in malnutrition (12).

Proper supplementation of food time is a key factor in a child's growth. The results of a study showed that mothers introduced additional foods too early for children can be a major factor contributing to the high incidence of malnutrition. The thing to be done is to ensure access to food additives, improve quality, and provide extra food in a timely manner to the children that since the age of 6 months (13).

Timeliness in feeding is an attempt to reduce body levels before cumulative age and become irreversible fissile stunting within 2 years. In this analysis, factors related to the minimum diet are available from 0,2 to 1,4 based on height according to age (14).

In addition, the results of other studies show that children receive additional food get an increase in height of 0,54 $\mathrm{cm}$ during the study period. Additional food provided by mothers who received nutrition education resulted in an increase in height of $0,49 \mathrm{~cm}$ in children aged 6 months to 2 years (15). Children over the age of 18 months (ages 18-36 months) who are given additional feeding interventions will increasingly increase children's height by $1.5 \mathrm{~cm}(1.0$ cm per year) (16).

Nutritional intake plays an important role in the child's growth process, so that to achieve optimal growth and development, nutritional intake must be met. At the age of 6 months, exclusive breastfeeding does not adequately meet the nutritional needs of children, so an additional source of nutrients is needed with complementary foods. If the intake of nutrients is inadequate, the frequency of eating and portion sizes are very low then it can cause poor nutritional status in children. Supplementary feeding, there must be a source of macronutrients and micronutrients that play a role in linear growth in children (11).

It has also been recommended by WHO and UNICEF to provide supplementary food suitable for children over 6 months in addition to breastfeeding from ages 6 to 24 months. It become one of the most effective interventions to prevent child mortality, ensure optimal nutrition and growth, and protect against long-term chronic diseases (17). In addition, increasing complementary feeding has proven to be the most effective for increasing child growth and contributing to reducing stunting (18).

On a population basis, the recommended frequency (assuming a diet with energy density $\geq 0,8 \mathrm{kcal} / \mathrm{gram}$ and low ASI intake) is 2-3 meals/day for babies aged 6-8 months (consumption of "finger food"); 3-4 meals/day for babies aged 9-11 months and children 12-24 months (most children can eat family food); and additional nutritious snacks that can be offered 1-2 times/day according to the child's wishes. When babies grow, complementary food foods must change from semi-solid to solid food and various foods offered must increase(19).

Increased energy density may be effective for environments that have low energy and babies cannot compensate by increasing the volume of healthy food, but also, this strategy cannot affect growth (20).

Supplementary food must vary every day; includes sufficient amount of meat, poultry, or eggs; as well as fruit and vegetables rich in vitamin A. If not possible, can be replace by consuming fortified supplementary food, vitamins, and minerals to ensure the adequacy of certain 
nutritional intake (19). The use of complementary foods or instant-fortified or ready-to-use supplements (such as fat-based nutritional supplements) can reduce the risk of infection because it can easily be prepared before serving, thereby reducing the possibility of contamination when cooling is not available (21).

However, the results of the Chinese study showed that the prevalence of stunting in children aged 6-59 months increased, with a peak of $25.4 \%$ at 24 months and 35 months. This shows that from the introduction of complementary foods, children's caloric and protein intake is insufficient due to the poor quality of complementary food in the form of flour gruels, especially in rural areas. Although whole grains can provide a large portion of energy for children to grow and develop, they cannot be used for anabolism and rebuilding tissue, resulting in low linear growth in children. Therefore, it is necessary to add protein in supplementary foods for children's diets to improve the growth and development of children (22).

\section{LIMITATIONS}

Limitations of this study is that not all the variables in the Nutritional Status Monitoring can be analyzed, such as variable blood supplementation in young women with a sample of young women who receive iron tablet for Nutritional Status Monitoring. In addition, in this study it was assessed that there was information bias in the form of recall bias when interviewing PSG data collection using questionnaires. Information bias is a deficiency in measuring exposure or output data which results in different information accuracy between groups compared (23).

\section{CONCLUSION}

One prevention of stunting is by giving supplementary feeding to children under two years old. This can be seen in the results of research that children under two years old who do not get supplementary food are at a higher risk for stunting than children under 2 years old who get supplementary food. Health workers at the primary health care should be clear to inform mothers to provide supplementary food and vitamin A at the 6-24 month of age.

\section{ACKNOWLEDGE}

Thank you to Dr. Martya Rahmaniati M., S.Si, M.Si as lecturer from Department of Biostatistics and Population, Faculty of Public Health, University of Indonesia which has helped assistance in guidance. Thank you to the Directorate General of Nutrition of the Ministry of Health of the Republic of Indonesia which has helped with data of the Nutritional Status Monitoring 2017.

\section{REFERENCES}

1. Trisnawati Y, Purwanti S, Retnowati M. Studi Deskriptif Pengetahuan Dan Sikap Ibu Hamil Tentang Gizi 1000 Hari Pertama Kehidupan Di Puskesmas. Jurnal Kebidanan. 2016;VIII(02):175-82.

2. Prado E, Dewey K. Nutrition and Brain Development in Early Life. A\&T Technical Brief. 2012;(4).

3. Christian P, Murray-kolb LE, Katz J, Schaefer BA, Cole PM, Leclerq SC, et al. and Intellectual and Motor Function in Early School-aged Children in Nepal. JAMA. 2010;304(24):2716-23.

4. Mardianis. Analisis Implementasi Kebijakan Program 1000 Hari Awal Kehidupan Manusia oleh Dinas Kesehatan Kota Tanjungpinang. Universitas Maritim Raja Ali Haji; 2016.

5. UNICEF. Nutrition in the First 1,000 Days: State of the World's Mothers 2012. New York: Save the Children International; 2012.

6. Kemenkes RI. Hasil Pemantauan Status Gizi (PSG) 2017. Direktorat Gizi Masyarakat Direktorat Jenderal Kesehatan Masyarakat Kementerian Kesehatan. Jakarta; 2018.

7. Jones G, Steketee RW, Black RE, Bhutta ZA, Morris SS. How Many Child Deaths Can We Prevent This Year? The Lancet. 2003;362(9377):65-71.

8. Simanjuntak BY, Haya M, Suryani D, Ahmad CA. Early Inititation of Breastfeeding and Vitamin A Supplementation with Nutritional Status of Children Aged 6-59 Months. Kesmas: National Public Health Journal. 2018;12(3):107-13.

9. Hadi H, Stoltzfus RJ, Dibley MJ, Moulton LH, West $\mathrm{KP}$, Kjolhede CL, et al. Vitamin A supplementation selectively improves the linear growth of indonesian preschool children: results from a randomized controlled trial. The American journal of clinical nutrition. 2000;71(2):507-13.

10. UNICEF. Improving child nutrition: The achievable imperative for global progress. New York: UNICEF; 2013.

11. Hijra H, Fatimah-Muis S, Kartasurya MI. Inappropriate complementary feeding practice increases risk of stunting in children aged 12-24 months. Universa Medicina. 2016;35(3):146.

12. Udoh EE, Amodu OK. Complementary feeding practices among mothers and nutritional status of infants in Akpabuyo Area, Cross River State Nigeria. SpringerPlus. 2016;5(2073):1-19.

13. Awogbenja MD, Ugwuona FU. Feeding Practices and Nutritional Status of Under- Five Children In Nasarawa State, Nigeria. PAT. 2010;6(1):23-35.

14. Onyango AW, Borghi E, De Onis M, Del Carmen Casanovas M, Garza C. Complementary feeding and attained linear growth among 6-23-month-old children. Public Health Nutrition. 2014;17(9):1975-83. 
15. Imdad A, Yakoob MY, Bhutta ZA. Impact of maternal education about complementary feeding and provision of complementary foods on child growth in developing countries. BMC Public Health. 2011;11(S25):1-14.

16. Black RE, Allen LH, Bhutta ZA, Caulfield LE, Onis M de, Ezzati M, et al. Maternal and Child Undernutrition: Global and Regional Exposures and Health Consequences. The Lancet. 2008;371(9608):243-60.

17. World Vision. Improving the Health and Nutrition Status of Women and Children Promising Practices from East Africa. 2013.

18. UNICEF. Programming Guide Infant and Young Child Feeding. New York: UNICEF; 2011.

19. WHO. Complementary feeding. Switzerland: WHO; 2001.
20. Dewey KG. Reducing stunting by improving maternal, infant and young child nutrition in regions such as South Asia: Evidence, challenges and opportunities. Maternal and Child Nutrition. 2016;12:27-38.

21. Huffman SL, Schofield D. Consequences of malnutrition in early life and strategies to improve maternal and child diets through targeted fortified products. Maternal and Child Nutrition. 2011;7(SUPPL. 3):1-4.

22. Zhou H, Wang X-L, Ye F, Zeng XL, Wang Y. Relationship between child feeding practices and malnutrition in 7 remote and poor counties, P R China. Asia Pacific journal of clinical nutrition. 2012;21(2):234-40.

23. Last JM. A Dictionary of Epidemiology: Fourth Edition. New York: Oxford University Press; 2001. 